\title{
The prevalence of IgE-dependent sensitizations to selected trophoallergens and airborne allergens in the population of children and adolescents of the north-eastern region of Poland
}

\author{
Maciej Kaczmarski ${ }^{1}$, Dorota Citko ${ }^{2}$, Jolanta Wasilewska ${ }^{1,3}$
}

${ }^{1}$ Department of Paediatrics, Gastroenterology and Allergology, Medical University of Bialystok, Bialystok, Poland ${ }^{2}$ Department of Statistics and Medical Informatics, Medical University of Bialystok, Bialystok, Poland ${ }^{3}$ Centre for Paediatrics, Allergology, Psychodietetics and Treatment of Somatic Diseases in Children with Autism, Bialystok, Poland

Adv Dermatol Allergol 2020; XXXVII (5): 790-795 DOI: https://doi.org/10.5114/ada.2020.100490

\begin{abstract}
Introduction: Good evidence has been provided over the last three to four decades that the prevalence of allergic diseases has been increasing in many developed countries worldwide. Recent data suggest that this increase may now be levelling off.

Aim: Retrospective analysis of the prevalence of lgE-dependent sensitization and changes in selected environmental allergens in the population of children and adolescents in the north-eastern region of Poland in the years 1998-2012. Material and methods: Skin prick testing (SPT) with selected food allergens (trophoallergens) and airborne allergens was used to evaluate the sensitization process of patients recruited to the study in the years 1998-2012. A positive result of sensitization was defined when the patient had at least one positive skin prick test with the allergen studied. The skin prick tests were done after written consent had been obtained from the parents.

Results: The retrospective study included children and adolescents aged up to 18 years with a suspicion of an allergic disease, referred to the regional tertiary medical centre for further diagnosis. A total of 6577 patients were studied, including 1556 (23.7\%) in 1998, 1473 (22.4\%) in 2003, 1690 (25.7\%) in 2008, and 1858 (28.2\%) in 2012. Sensitization to at least one allergen was observed in $39.0 \%$ of the examined children (regardless of the allergen type), of which $8.1 \%$ were sensitized to food allergens only, $23.9 \%$ to airborne allergens only, and $7.0 \%$ simultaneously to food and airborne allergens. During the 14-year study period, an increase was noted in the percentage of the sensitized children from $35.3 \%$ at baseline to $40.4 \%$ when the study was completed. The percentage of those sensitized to food allergens increased from $10.5 \%$ (1998) to $20.1 \%$ (2012). The percentage of children sensitized to airborne allergens remained unchanged at the level of $28.2 \%$ in 1998 and $27.2 \%$ in 2012.

Conclusions: Measurement of skin prick test reactivity to different allergens is a useful and commonly used method in epidemiological studies for the assessment of allergic sensitization and changes in selected populations. The obtained results confirmed the need for systematic epidemiological research into allergic sensitization and allergic diseases among children and adolescents in Poland.
\end{abstract}

Key words: IgE-sensitization, trophoallergens, airborne allergens, skin prick tests.

\section{Introduction}

Good evidence has been provided over the last three to four decades that the prevalence of allergic diseases has been increasing in many developed countries world- wide [1-3]. Recent data suggest that this increase may now be levelling off [4-6].

Allergic diseases are the major illnesses particularly in childhood, being the most common cause of kindergarten or school absence among children as well as reduced life

Address for correspondence: Prof. Maciej Kaczmarski MD, PhD, Department of Paediatrics, Gastroenterology and Allergology, Medical University of Bialystok, Bialystok, Poland, e-mail: maciej.kaczmarski@umb.edu.pl Received: 13.02.2020, accepted: 27.03.2020. 
activity of their families. They are also a serious health problem in adults and create a significant burden of health care costs in some countries [7-9].

Sensitization is a specific, individual immune response of the human body to genetic and environmental factors. The effect of the immune reaction to their action is either the synthesis of specific lgE antibodies (atopic sensitization) or T-cell sensitization (allergic sensitization, priming). For most people, sensitization is clinically asymptomatic; appropriate allergy testing methods are used to identify the sensitization type. In atopic sensitization, allergenspecific lgE (slgE) antibodies are detected in the blood or skin of patients. To identify allergic sensitization, a culture of suspended mononuclear blood cells in a medium which contains a suspected allergen is used. It should be emphasized that sensitization is the first of the three stages in a person's potential development of an allergic disease. The lack of sensitization excludes completely the development of the subsequent phases (effector and chronic) that are important in the progression of allergic diseases [10-12]. Only some of the individuals with allergic sensitization demonstrate symptoms of an allergic disease at different ages. A pathological process caused by a harmful allergen occurs when specific pathogenic mechanisms: IgE-dependent, IgE-independent, mixed or cellular, are triggered in the sensitized body. These mechanisms lead to the development of allergic inflammation. Biological mediators of allergic inflammation damage anatomically or functionally the physiological functions of specific organs or systems, and determine the clinical manifestation of a specific allergic disease [13].

In the methodology of epidemiological research concerning the assessment of the incidence of allergic sensitization and prevalence of allergic diseases in selected populations, different tools and methods are used. They mainly include interview, questionnaire, telephone or electronic surveys [14-18].

The scores obtained by these methods are much higher than by using such objectifying methods as assessment of allergen-specific lgE antibodies (slgE) in blood and skin (Skin Prick Tests) or provocation tests with a specific allergen $[19,20]$. These methods allow determination of the type and scale of the current IgE-dependent sensitivity with selected food and airborne allergens.

The sensitization process was analysed in the years covered by the study, and the obtained results enabled us to compare sensitization of the paediatric population in this region of Poland during a 14-year period.

\section{Aim}

Assessment of the incidence of IgE-dependent sensitization to selected environmental allergens of children and adolescents in the north-eastern region of Poland in the years 1998-2012.

\section{Material and methods}

Skin prick tests (SPT)

The tool for monitoring the sensitization process of patients recruited to this study (1998-2012) was skin prick testing (SPT) with selected food allergens (trophoallergens) and airborne allergens (aeroallergens). The SPT results provided information on the type and scale of sensitization of the study group in a given year of the study. The SPTs were carried out according to the recommendations of the European Academy of Allergy and Clinical Immunology $[19,20]$. The presence of sensitization was detected on the basis of a positive skin test response when the diameter of the wheal formed after introducing an allergen was not less than $3 \mathrm{~mm}$ in comparison to the negative control [19]. The set of allergens for skin prick testing included 12 native foods (cow's milk proteins, soybeans, peanuts, egg white, hen's egg, chicken meat, beef, wheat flour, banana, fish, sesame, mandarin) and 6 airborne allergens (commercial aeroallergens) from Allergopharma (house dust mite, cat's fur, dog's fur, grass, trees and weeds).

The following terms were used to interpret the obtained SPT results:

- sensitization - a positive skin test for at least one allergen (regardless of the allergen type),

- sensitization to food allergens - a person who has a positive skin test for at least one food allergen,

- sensitization to food allergens only - a person who has a positive skin test for at least one food allergen and who has not been allergic (negative skin test) to any airborne allergens,

- sensitization to airborne allergens - a person who has a positive skin test for at least one airborne allergen,

- sensitization to airborne allergens only - a person who has a positive skin test for at least one airborne allergen and who has not been allergic (negative skin test) to any food allergens,

- simultaneous sensitization to food and airborne allergens - a person who has a positive skin test for at least one food allergen and at the same time a positive skin test for at least one airborne allergen.

\section{Study group}

This retrospective study included children and adolescents aged up to 18 years and referred for further diagnostics to the regional tertiary care centre with a suspicion of an allergic disease (i.e. to the Outpatient Clinic or Department of Paediatrics, Gastroenterology, and Allergology, Medical University of Bialystok, Poland).

A total of 6577 children were studied, including 1556 (23.7\%) studied in 1998, 1473 (22.4\%) in 2003, 1690 (25.7\%) in 2008, and 1858 (28.2\%) in 2012 (Table 1).

The distribution of the study children in the years from 1998 to 2012 according to age, sex and season at birth is shown in Table 2. 
No significant relationships were observed between sex and the year of the study $(p>0.05)$ or between the season at birth and the year studied $(p>0.05)$. A statistically significant relationship was found between children's age (in subgroups) and the year studied ( $p<0.0001$ ). The year 2012 showed a higher percentage of children aged up to 3 years in comparison to the previous years (Table 2).

In 2012, the median age of patients was 4 years, in previous years -6 years. Detailed comparisons of posthoc tests showed that the age distribution of the children examined in 2012 differed significantly from the age distribution of those examined in 1998 ( $\left.p^{* *}<0.0001\right)$, in $2003\left(p^{\star *}<0.0001\right)$, in 2008 ( $\left.p^{\star *}<0.0001\right)$ ( $^{* *}$ post-hoc comparisons for average ranks of all group pairs).

The age distribution of patients in the respective years is shown in Figure 1.

\section{Statistical analysis}

The Shapiro-Wilk test was used to test for the compatibility of distributions of measurable variables with normal distributions. Due to strong asymmetrical distributions of measurable variables, positional parameters (median, quar-

Table 1. Distribution of the studied children by year

\begin{tabular}{lcc}
\hline Year of study & Number studied & Percentage \\
\hline 1998 & 1556 & 23.7 \\
\hline 2003 & 1473 & 22.4 \\
\hline 2008 & 1690 & 25.7 \\
\hline 2012 & 1858 & 28.2 \\
\hline Total & 6577 & 100.0 \\
\hline
\end{tabular}

ter) were determined and nonparametric methods were used. The Kruskal-Wallis test and post-hoc tests for average ranks of groups were used to compare the distribution of independent variables. Nominal variables were described in terms of counts and percentages. The $\chi^{2}$ test of independence was used to study the relationship between qualitative variables. A significance level of $\alpha=0.05$ was assumed for the verification of hypotheses.

\section{Results}

\section{Sensitization to at least one allergen}

Sensitization to at least one allergen was observed in $39.0 \%$ of the examined children (regardless of the allergen type), of which $8.1 \%$ were sensitized to food allergens only, $23.9 \%$ to airborne allergens only, and $7.0 \%$ were sensitized simultaneously to food and airborne allergens (Table 3).

Our results concerning the incidence of sensitization from the first year of the study were compared with those obtained every 3 years. The final results allowed the authors for a dynamic evaluation of the sensitization process of the examined patients within the analysed 14 years (Figures 2,3 ).

The percentage of the sensitized children (sensitization regardless of the allergen type) accounted for 35.3\% in the first analysed year (1998) and reached $40.4 \%$ in 2012 (14-year period). The percentage of paediatric patients sensitized to airborne allergens was 28.2\% in 1998 and did not differ statistically significantly from that found in 2012 (27.2\%). Interestingly, an increase was noted in the percentage of children sensitized to food allergens from $10.5 \%$ in 1998 to $20.1 \%$ in 2012 , when the study was completed. The results are presented in Figures 2 and 3.

Table 2. Distribution of children in various years of the study according to sex, age, season at birth

\begin{tabular}{|c|c|c|c|c|c|c|c|}
\hline \multicolumn{2}{|l|}{ Characteristics } & \multirow{2}{*}{$\begin{array}{l}\text { Total } \\
n / \%\end{array}$} & \multirow{2}{*}{$\begin{array}{c}1998 \\
n / \%\end{array}$} & \multirow{2}{*}{$\begin{array}{c}2003 \\
n / \%\end{array}$} & \multirow{2}{*}{$\begin{array}{c}2008 \\
n / \%\end{array}$} & \multirow{2}{*}{$\begin{array}{l}2012 \\
n / \%\end{array}$} & \multirow[t]{2}{*}{$P$-value* } \\
\hline & & & & & & & \\
\hline \multirow[t]{2}{*}{ Sex } & Female & $3105 / 47.2$ & $712 / 45.8$ & $713 / 48.4$ & $840 / 49.7$ & $840 / 45.2$ & 0.052 \\
\hline & Male & $3472 / 52.8$ & $844 / 54.2$ & $760 / 51.6$ & $850 / 50.3$ & $1018 / 54.8$ & \\
\hline \multirow[t]{5}{*}{ Age [years] } & Up to 3 & $1970 / 29.9$ & $402 / 25.8$ & $314 / 21.3$ & $386 / 22.8$ & $868 / 46.7$ & $<0.0001$ \\
\hline & $4-7$ & $2457 / 37.4$ & $597 / 38.4$ & $585 / 39.7$ & $688 / 40.7$ & $587 / 31.6$ & \\
\hline & $8-12$ & $1245 / 18.9$ & $349 / 22.4$ & $314 / 21.3$ & $360 / 21.3$ & 222/11.9 & \\
\hline & $13-18$ & $867 / 13.2$ & $193 / 12.4$ & $251 / 17.1$ & $255 / 15.1$ & $168 / 9.1$ & \\
\hline & Missing $^{\star *}$ & $38 / 0.6$ & $15 / 1.0$ & $9 / 0.6$ & $1 / 0.1$ & $13 / 0.7$ & \\
\hline \multirow[t]{5}{*}{ Season at birth } & Spring & $1729 / 26.3$ & $404 / 26.0$ & $404 / 27.4$ & $469 / 27.8$ & $452 / 24.3$ & 0.5934 \\
\hline & Summer & $1693 / 25.7$ & $398 / 25.6$ & $372 / 25.3$ & $445 / 26.3$ & $478 / 25.7$ & \\
\hline & Autumn & $1588 / 24.1$ & $370 / 23.8$ & $351 / 23.8$ & $394 / 23.3$ & $473 / 25.5$ & \\
\hline & Winter & $1516 / 23.1$ & $363 / 23.3$ & $337 / 22.9$ & $381 / 22.5$ & $435 / 23.4$ & \\
\hline & Missing $^{\star *}$ & $51 / 0.8$ & $21 / 1.3$ & $9 / 0.6$ & $1 / 0.1$ & 20/1.1 & \\
\hline
\end{tabular}

${ }^{*} \chi^{2}$ test of independence, ${ }^{* *}$ missing data. 


\section{Discussion}

Epidemiological data of the last three to four decades indicate that the prevalence of allergic diseases among residents of countries with high economic and hygienic standards is systematically increasing. This trend includes both developmental age populations and adults $[1,14,21,22]$.

The problem of the prevalence of allergic sensitization and the ensuing development of allergic diseases concerns the populations of children and adolescents worldwide [14]. The results of epidemiological studies described in the literature on the incidence/prevalence of allergic diseases in different populations are diverse $[3,4,6,18]$. The discrepancies are caused by different inclusion criteria for research participants: the size and type of the study groups, different sex and age distributions, health status, place of residence, eating and hygiene habits. These research criteria as well as different study methods used are very important when comparing this type of research conducted in various countries [3, 18, 22-28]. For these reasons, data from epidemiological studies need to be constantly verified and updated [8, 18, 29]. In a significant part of allergy-related publications, the skin prick tests (SPTs) are used as a method to assess sensitization or to determine the cause of allergic symptoms of the study populations. The method is quick, simple to perform and fairly inexpensive [30].

It should be mentioned that a few studies have been conducted so far on the type and incidence of allergic sensitization/diseases among Polish residents.

The first research was performed in 1993, using a questionnaire as the main research tool. However, this study omitted the Polish youngest age group, i.e. children up to 3 years old [23].

In the years 2006-2008, the Epidemiology of Allergic Diseases in Poland (ECAP) study was conducted. The prevalence of allergic diseases and asthma was assessed. The telephone questionnaire interview concerned three age groups: children aged 6-7 years, $13-14$ years, and adults aged $20-44$ years. Positive skin test results were observed in $39.3 \%$ of children aged $6-7$ years and $46.8 \%$ of children aged 13-14 years [31-33].

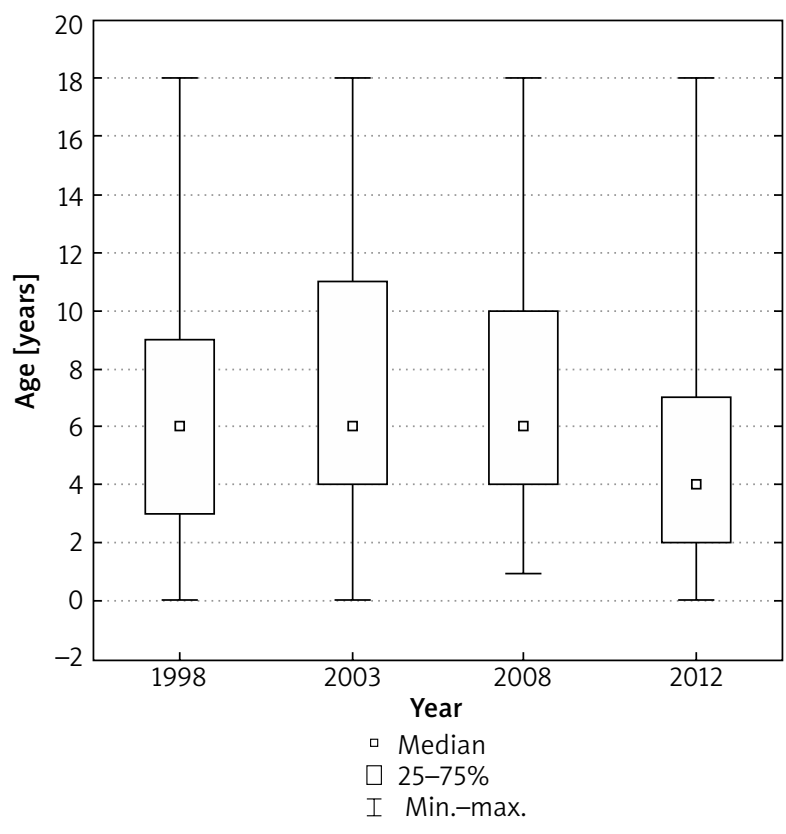

Figure 1. Distribution of patients' age by year

A study involving the general Polish population of the Lodz Province with patients aged $3-80$ years showed that $25.4 \%$ of children and $24.0 \%$ of adults were sensitized to at least one allergen (airborne allergens only were analysed) [34].

Rymarczyk and Rogala assessed the prevalence of food allergy in the Silesian population in a group of 796 randomly chosen patients at a mean age of 41.5 years. Using a questionnaire, they found that 196 (24.5\%) people reported undesirable reactions after the consumption of certain food products. None of them had any skin test performed [35].

This paper presents our results of the research into the prevalence of sensitization to food and airborne allergens among patients in a developmental age with suspected symptoms of allergy, living in the north-eastern region of Poland. As a research tool, the method of skin prick tests was chosen, allowing the authors to objectively assess the process of sensitization in the Polish population. Poland is a homogeneous country in terms

Table 3. Prevalence of sensitization among the studied children in the years 1998-2012

\begin{tabular}{|c|c|c|}
\hline Prevalence & Number & Percentage \\
\hline Sensitization (regardless of the allergen type) & 2565 & 39.0 \\
\hline Sensitization to food allergens & 996 & 15.1 \\
\hline Sensitization to airborne allergens & 2030 & 30.9 \\
\hline Sensitization to food allergens only & 537 & 8.1 \\
\hline Sensitization to airborne allergens only & 1571 & 23.9 \\
\hline Sensitization to both food and airborne allergens & 459 & 7.0 \\
\hline
\end{tabular}




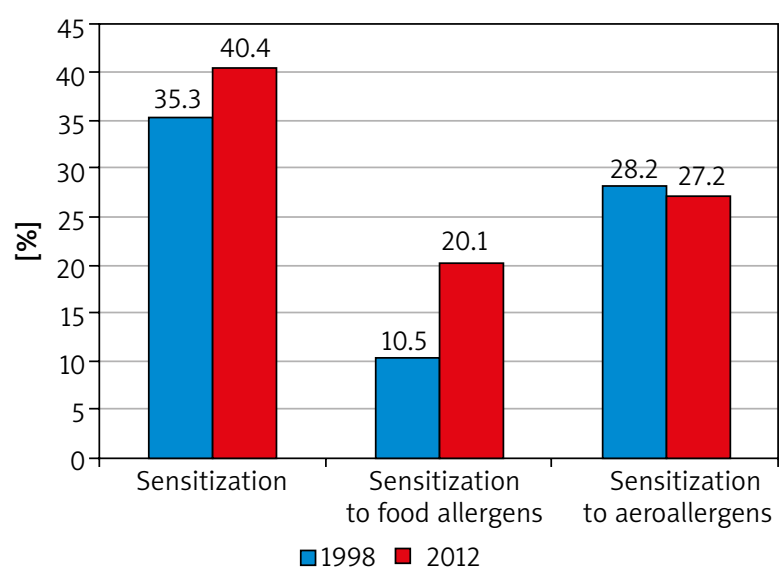

Figure 2. The prevalence of allergic sensitization in the study group in 1998 as compared to 2012

of ethnicity, culture and rules of nutrition and hygiene; therefore, the results obtained from the regional research can be considered representative of the entire country. In addition, the uniqueness of the current study is that the analysis of the frequency and type of sensitization involved patients with a suspected allergic disease aged from 2 to 18 years. Among the available publications analysing the results of skin prick tests, none referred to such age ranges.

During the research period, sensitization to at least one allergen was observed in $39.0 \%$ of the children examined (regardless of the allergen type); $15.0 \%$ of the children being hypersensitive to food allergens (trophoallergens) and 31.0\% to airborne allergens (aeroallergens).

In the study group, $8.1 \%$ were sensitized to food allergens only, $23.9 \%$ to airborne allergens only, and $7.0 \%$ were sensitized simultaneously to food and airborne allergens.

The predominant group consisted of patients sensitized to aeroallergens, the causative agents predisposing to such allergic diseases as asthma or allergic rhino-conjunctivitis. The hypersensitive children predisposed to the development of food or skin allergies constituted a much smaller group.

Importantly, within the 14-year study period, the percentage of patients sensitized to airborne allergens who underwent retrospective analysis was not increased, whereas that of patients with food allergy increased twice: from 10.5\% in 1998 to $20.1 \%$ in 2012. This rise referred to all food allergens (12) examined using the SPT.

The results presented in this paper should be interpreted with consideration of the following limitations. Firstly, SPTs were performed by four people during the 14-year period; despite their high qualifications (allergic diseases specialists), there was a possibility of various uses of the lancet. The classical method uses a lancet at an angle of $90^{\circ}$ and in the modified method the lancet's angle of inclination was from $30^{\circ}$ to $70^{\circ}$, which may cause a dif-

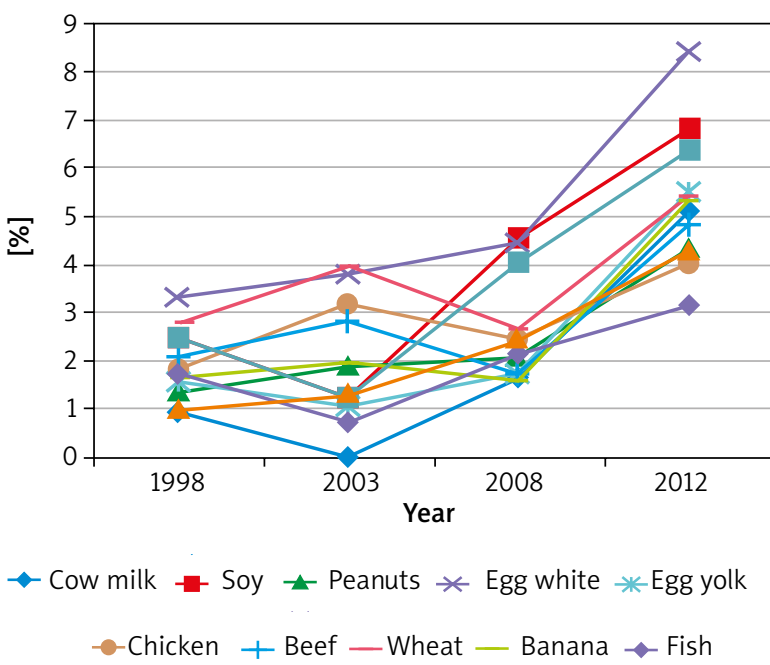

Figure 3. The prevalence of sensitization to the respective food allergens observed in time intervals within the 14-year study period

ference in the amount of the allergen introduced to the skin. Secondly, the assessment of the SPT results may differ depending on the specialist performing the tests. The coefficient of variation (CV) was $25.0 \%$ for negative control and $16.6 \%$ for positive control, respectively.

\section{Conclusions}

IgE-dependent sensitization to food and airborne allergens assessed by skin prick tests in the years 19982012 concerned $39.0 \%$ of the paediatric population living in the north-eastern region of Poland. In the years 1998-2012, in the population of children and adolescents studied, an increase was noted in the percentage of patients sensitized to food allergens.

\section{Acknowledgments}

This project was funded by the Medical University of Bialystok, Poland. The Bioethics Committee Approval No. R-I-002/233/2009.

Maciej Kaczmarski is Professor emeritus, head of the department in the years 1990-2014.

\section{Conflict of interest}

The authors declare no conflict of interest.

\section{References}

1. Isolauri E, Hurre A, Salminen S, Impivaara O. The allergy epidemic extends beyond the past few decades. Clin Exp Allergy 2004; 34: 1007-10.

2. Prescott SL, Allen KJ. Food allergy: riding the second wave of the allergy epidemic. Pediatr Allergy Immunol 2011; 22: 155-60. 
3. Prescott SL, Pawankar R, Allen KJ, et al. A global survey of changing patterns of food allergy burden in children. WAO J 2013; 6: 1-12.

4. Govaere E, Van Gysel D, Verhamme K, et al. The association of allergic symptoms with sensitization to inhalant allergens in childhood. Pediatr Allergy Immunol 2009; 20: 448-57.

5. Novak D, Suppli UC, von Mutius E. Asthma and atopy; has peak prevalence been reached? Eur Respir J 2004; 23: 359-60.

6. Burney PG, Potts J, Kummeling I, et al. The prevalence and distribution of food sensitization in European adults. Allergy 2014; 69: 365-71.

7. Mendis S. Contribution of allergy to the burden of non-communicable disease. In: Global Atlas of Allergy, editors Akdis CA, Agache I. EAACI 2014; 336-7.

8. Pawankar R, Canonica GW, Holgate ST (eds). World Allergy Organization (WAO) White Book on Allergy: WAO 2011.

9. Guest JF, Weidlich D, Kaczmarski M, et al. Relative costeffectiveness of using an extensively hydrolyzed casein formula containing the probiotic Lactobacillus rhamnosus GG in managing infants with cow's milk allergy in Poland. ClinicoEcon Outcomes Res 2016; 8: 307-16.

10. Sellge G, Bischoff SC. The immunological basis of IgE mediated reactions. In: Food Allergy. Adverse Reactions to Foods and Food Additives. $4^{\text {th }}$ ed. Metcalfe D, Sampson HA, Simon RA (eds). Blackwell Publishing 2008; 15-28.

11. Romagnani S. Th1/Th2 paradigm. Immunol Today1997; 18: 263-6.

12. Claassen JL, Levine AD, Buckley RH. Recombinant human IL-4 induces IgE and IgG synthesis by normal and atopic donor mononuclear cells. Similar dose response, time course, requirement for $\mathrm{T}$ cells, and effect of pokeweed mitogen. J Immunol 1990; 144: 2123-30.

13. Zellweger F, Eggel A. IgE-associated allergic disorders: recent advances in etiology, diagnosis, and treatment. Allergy 2016; 71: 1652-61.

14. Asher MI, Montefort S, Björksten B, et al. Worldwide time trends in the prevalence of symptoms of asthma, allergic rhinoconjunctivitis, and eczema in childhood: ISAAC Phases One and Three repeat multicountry cross-sectional surveys. Lancet 2006; 368: 733-43.

15. Genuneit J, Seibold AM, Apfelbacher C, et al. Overview of systematic reviews in allergy epidemiology. Allergy 2017; 72: 849-56.

16. Bousquet J, Caimmi DP, Bedbrook A, et al. Pilot study of mobile phone technology in allergic rhinitis in European countries: the MASK-rhinitis study. Allergy 2017; 72: 857-65.

17. Botha M, Basera W, Facey-Thomas HE, et al. Nutrition and allergic diseases in urban and rural communities from the south African Food Allergy cohort. Pediatr Allergy Immunol 2019; 30: 511-21.

18. Kaczmarski M, Bartuzi Z. Epidemiological aspects of food allergy in children and adults. Pol J Allergol 2016; 3: 46-55.

19. Dreborg S, Frew A. Position paper: allergen standardization and skin tests. The European Academy of Allergology and Clinical Immunology. Allergy 1993; 48 (Suppl 14): 49-82.

20. Allergy Diagnosis. In: Global Atlas of Allergy. Akdis CA, Agache I (eds.). EAACI 2014; 150-72.

21. Leynaert B, Neukirch C, Kony S, et al. Association between asthma and rhinitis according to atopic sensitization in a population-based study. J Allergy Clin Immunol 2004; 113: 86-93.

22. Kaczmarski M, Wasilewska J, Jarocka-Cyrta E, et al. Original paper. Polish statement on food allergy in children and adolescents. Adv Dermatol Allergol 2011; 28: 331-67.
23. Nwaru BI, Hicstein L, Panesar SS, et al. The epidemiology of food allergy in Europe: a systematic review and metaanalysis. Allergy 2014; 69: 62-75.

24. Osterballe M, Hansen TK, Mortz CG, et al. The prevalence of food hypersensitivity in an unselected population of children and adults. Pediatr Allergy Immunol 2005; 16: 567-73.

25. Rona R, Keil T, Summers C, et al. The prevalence of food allergy: a meta-analysis. J Allergy Clin Immunol 2007; 120: 638-46.

26. Kaczmarski M, Wasilewska J, Cudowska B, et al. The natural history of cow's milk allergy in north-eastern Poland. Adv Med Sci 2013; 58: 22-30.

27. Schneider JJ, Newberry SJ, Riedl MA. Diagnosing and managing common food allergies. JAMA 2010; 303: 1848-56.

28. Schoemaker AA, Sprikkelman AB, Grimshaw KE, et al. Incidence and natural history of challenge-proven cow's milk allergy in European children - EuroPrevall birth cohort. Allergy 2015; 70: 963-72.

29. Papadopulos NG, Agache I, Bavbek S, et al. Research needs in allergy: an EAACl position paper in collaboration with EFA. Clin Transl Allergy 2012; 2: 21.

30. Norrman G, Falth-Magnusson K. Adverse reactions to skin prick testing in children- prevalence and possible risk factors. Pediatr Allergy Immunol 2009; 20: 273-8.

31. Samoliński B, Raciborski F, Lipiec A, et al. Epidemiologia chorób alergicznych w Polsce (ECAP). Pol J Alergol 2014; 1: 10-8.

32. Dor-Wojnarowska A, Liebhart J, Miecielica JB, et al. The impact of sex and age on the prevalence of clinically relevant sensitization and asymptomatic sensitization in the general Population. Arch Immunol Ther Exp 2017; 65: 253-61.

33. Samel-Kowalik P, Lipiec A, Tomaszewska A, et al. Występowanie alergii i astmy w Polsce. Badania ECAP. Gazeta Farmaceutyczna 2009; 3: 32-4.

34. Kupryś-Lipińska I, Elgalal A, Kuna P. Skin prick test with inhaled allergens in the general population of Lodz province. Pneumonol Alergol Pol 2009; 77: 229-34.

35. Rymarczyk B, Rogala B. Częstość występowania i charakterystyka reakcji nadwrażliwości na pokarmy w populacji śląskiej. Alergia Astma Immunol 2009; 14: 248-51. 